\title{
Considerações acerca do belo em Kant e Gadamer: um possível para além da objetividade científica
}

\author{
RODRIGO VIANA PASSOS *
}

\begin{abstract}
RESUMO O presente artigo tem por escopo propor uma provisória leitura hermenêutico-fenomenológica sobre a doutrina do belo kantiana. Essa leitura toma por base "metodológica” as reflexões de Hans-Georg Gadamer esposadas em Verdade e Método - em especial a primeira parte -, bem como em artigos periféricos que suportem nossas pretensões. Buscamos com isso refletir se há em Kant uma reflexão acerca da experiência do belo como extravagante em relação às pretensões epistemológicas da ciência moderna. Dedicaremos especial atenção à ideia kantiana de um jogo sem conceitos no juízo estético, bem como sua posição enquanto juízo reflexionante. Por seu turno, a partir das considerações gadamerianas extrairemos sua tarefa de reabilitar o âmbito de verdade para a arte, em detrimento do padrão das ciências da natureza.
\end{abstract}

PalaVRas-chave Gadamer; Kant; Belo; Arte; Hermenêutica.

INTRODUÇÃo

O objetivo da ciência é aniquilar o mundo.

Friedrich Nietzsche

Gostaríamos de realizar aqui algo de provisório acerca de Kant e Gadamer. A partir das reflexões acerca do juízo estético naquele, e de uma hermenêutica da obra de arte neste, buscar-se-á articular algo de propositivo para nossa condição contemporânea. Esta condição diz no fundo: com o avanço do conhecimento técnico-científico é cada vez mais raro algum tipo de experiência contemplativa-extática (admiração) com o

* Mestrando em Filosofia

Programa de pós-graduação em Filosofia PUC-Rio 
mundo; quando muito, cai-se no âmbito do gozo momentâneo e da ânsia pela novidade - especialmente do âmbito da tecnologia e entretenimento. Não é a intenção promover um saudosismo por uma época idílica perdida, em que homem e mundo estariam em perfeita harmonia vital etc. Partamos simplesmente do pressuposto básico de que nossa experiência de mundo é daquela ordem e que isso se insere em um desenrolar histórico próprio ainda não tão preciso (se é que pode ser precisado).

O filósofo alemão Hans-Georg Gadamer foi um bastião importante nesse debate na segunda metade do séc. XX. Em Verdade e Método ele nos apresenta sua preocupação com o movimento voraz das ciências da natureza (Naturwissenschaften) em seu afã de se impor como paradigma maior do saber humano. Tanto é assim, que as próprias ciências do espírito (Geisteswissenschaften) buscarão no modelo metodológico daquelas a sua própria legitimação enquanto ciência. Todavia, para Gadamer elas fazem mal em seguir tal paradigma metodológico. Com tal postura subserviente, as ciências humanas velam sua possibilidade mais própria enquanto saber sobre o humano: compreendê-lo enquanto ser finito e em constante formação com o mundo, algo que escapa ao desejo de acabamento matemático-conceitual das ciências naturais. Além disso, seguindo os passos de Martin Heidegger, acreditamos que o conhecimento científico, se solto à própria sorte e recepcionado passivamente sob a lógica do progresso, levar-nos-á ao desencantamento do mundo ${ }^{1}$. Em resposta a isso, Gadamer se servirá justamente da via aberta pela experiência do belo na arte como via de reconciliação com o mundo e com nós mesmos.

Nesse sentido, pensamos que podemos encontrar também em Kant um gesto de preocupação sobre o destino do homem em seu progresso científico. É-nos provavelmente lícito, a partir da Crítica da Razão Pura, termos claro que Kant é um otimista em relação à ciência empírico-matemática e aos avanços de seu tempo. Tão otimista e maravilhado, que ele se impõe a tarefa de pôr a própria filosofia nos caminhos seguros da ciência moderna ${ }^{2}$. Com sua primeira crítica, Kant nos oferece uma arquitetônica do entendimento, o conhecimento objetivo (teórico) que é o fundamento para qualquer ciência empírica. Por outro lado, com a Crítica da Razão Prática Kant estará voltado para a faculdade que determina nossa vontade segundo um conceito de li-

1 Cf. HEIDEGGER, O tempo da imagem do mundo. In: Caminhos de Floresta.

2 Cf. KANT, Crítica da Razão pura, p. 5-35. 
berdade (conhecimento prático), e, enquanto tal, poder-se-ia dizer ser o âmbito mais próprio do ser humano enquanto ser racional e livre³. Aqui já vemos um caminho muito consequente assumido por Kant, qual seja, o de não relegar o humano à mera esfera da racionalidade objetiva e científica, cuidando para compreender âmbitos que revelem sua capacidade de pensar e determinar-se de acordo com tal. Nesse sentido, ele não é apenas um autômato que responde a estímulos externos.

Noutro giro, enfim, cremos que a Crítica da Faculdade de Julgar, principalmente com a determinação do juízo estético, é um caminho convergente nesse sentido: um para além da objetividade e do conceito na experiência do belo ${ }^{4}$ - fundamentalmente na natureza, diga-se -, um modo imediato de contemplação da harmonia do mundo. Sabemos que a terceira crítica kantiana abrange propósitos e temas outros que este. Mesmo assim, entendemos ser oportuno voltarmos nossa atenção para esse aspecto possível de sua obra.

Isto posto, tentaremos promover um acordo entre ambos no que diz respeito ao problema levantado inicialmente. Um acordo que deverá tentar superar as barreiras do tempo e do próprio criticismos que Gadamer reserva a alguns aspectos da obra kantiana. Para a tanto, a forma e um tom ensaísticos talvez se sobressaiam, mas o que nos importará mais é levantar questões.

\section{O METOdologismo CIENTífico E O CARÁTER DE VERDADE DA ARTE}

Nele, portanto, definitivamente, o deus nos mostra, para que não duvidemos, que não são humanos estes belos poemas, nem de homens, mas divinos e de deuses, e os poetas não são nada além de intérpretes dos deuses, possuídos por aquele que possui cada um. Demonstrado isso, o deus, intencionalmente, através do mais medíocre poeta, cantou o mais belo poema lírico

Platão. Íon, 534e-535a

É bem verdade que Gadamer tece crítica sensíveis ao pensamento kantiano, em especial à subjetivação estética promovida na Crítica da Faculdade de Julgar. Todavia, não adentraremos no mérito dessa questão específica. Tomaremos o pensamento

3 Cf. KANT, Crítica da Razão prática, p. 23.

4 Cf. KANT, Crítica da Faculdade do Juízo, p. 1-32. 
gadameriano aqui somente no tocante à sua problematização do paradigma científico da modernidade e seus efeitos sobre o modo do homem lidar com o mundo e como a experiência do belo na arte é uma alternativa a esse paradigma. Portanto, Gadamer será nosso privilegiado introdutor da questão. Todavia, comecemos com Heidegger:

O que acontece aqui? O que está na obra em obra [im Werk am Werk]? O quadro de van Gogh é a abertura daquilo que o utensílio, o par de sapatos do camponês, é em verdade. Este sendo [Dieses Seinende] emerge para o desvelamento [Unverborgenheit] do seu ser. Os gregos nomearam aletheia o desvelamento do sendo. Nós dizemos verdade e pensamos muito pouco em relação a esta palavra. Na obra está em obra um acontecer da verdade [im werk is ... ein Geschehen der Wahrheit am Werk], se aqui acontece uma abertura inaugurante do sendo naquilo que ele é e como ele é. Na obra de arte, a verdade do sendo pôs-se em obra. "Pôr" diz aqui: trazer para o permanecer. Um sendo, um par de sapatos de camponês, vem, para o permanecer na luz do seu ser, na obra. O ser do sendo vem para o constante do seu brilhar [seines Scheinens]. ${ }^{5}$

O que temos aqui? Uma obra de arte como fonte da verdade. Para Gadamer (e também Heidegger), uma tal compreensão do modo de ser da arte é barrada pelo paradigma da ciência moderna. Por um lado, a arte deve ser apenas objeto estético; por outro, tão somente a linguagem proposicional e uma metodologia empiricamente experimentada podem, segundo o modelo das ciências naturais, dar conta da verdade objetiva do mundo. Verdade aí tem a ver com controle. Controle dos dados da experiência, dominação do mundo: certeza. Há nesse gesto, portanto, a pretensão de uma subjetividade superar sua precariedade enquanto ser finito. Se não é bem um desejo secreto de onisciência e omnipotência - ser como um deus -, é pelo menos o exaurimento das possibilidades daqueles objetos que podem estar à mão: detalhar todos os aspectos físico-químico-biológicos de um peixe; determinar todos os elementos de uma rocha; definir, numa proposição matemática perfeita, a chave do universo; ou mesmo o controle objetivo da vida humana - vislumbrado, por exemplo, com a adesão das ciências do espírito às máximas das ciências da natureza. Isso é a luta contra a tragicidade da vida humana ${ }^{6}$.

5 HEIDEGGER, A origem da obra de arte, p. 87.

6 Cf. GADAMER, Verdad y Método, p. 31-75; e também A verdade nas ciências do espírito. In: Verdade e Método II: complementos e índice, p. 49-56. 
Eis a questão posta. Para Gadamer, bem como para Heidegger, trata-se de reabilitar o poder da obra de arte num mundo dominado pela técnica. Aproveitando-nos das intelecções heideggerianas, vemos uma saída possível. Tome-se o exemplo do par de sapatos. Sua existência é tão habitual em nosso dia-a-dia, que pouco nos damos conta de sua presença. Calçamos, sabemos que é de material tal, que é macio etc. Não há mais nada a saber sobre um mísero par de sapatos: não há surpresa. Todavia, como bem expõe Heidegger, com sua pintura van Gogh nos reapresenta o par de sapatos, prendendo nosso olhar nessa nova aparição. Algo brilha aí de inaudito. Aparentemente, um par de sapatos não era apenas aquilo que pretendíamos saber sobre ele. Poderíamos até dizer - contrariando talvez Heidegger: o belo luze na pintura de van Gogh. Contudo, devemos dizer também que o belo está aí somente para aquele que tem olhos para ele, ou seja, que se dispõe a contemplá-lo em seu acontecimento.

A experiência conquistada junto ao belo "em uma" obra de arte nos lança a um questionamento imediato sobre aquilo que postulamos como evidência - inclusive o mais recente descobrimento/invenção científico (a). Aí a subjetividade conhecedora, armada de seu arcabouço proposicional-conceitual, é jogada ao nada de uma aporia oriunda do questionamento feito pela obra. Se nos for permitida a analogia, diremos que toda obra de arte exerce - se recepcionada adequadamente, amigavelmente - o poder questionador e irônico do Sócrates platônico ${ }^{8}$.

Por isso, a familiaridade com a qual a obra de arte nos toca é ao mesmo tempo abalo e derrocada do habitual. Não é apenas o "É isso que tu és" que ela descobre em um espanto alegre e terrível - ela também nos diz: “Tu precisas mudar a tua vida $9 "$.

Com essas breves palavras nem de longe esgotamos o tema da verdade da arte em Heidegger e Gadamer, mas acreditamos ter exposto o sentido geral que pretendemos seguir no que concerne à teoria kantiana do belo. Temos consciência de que Kant não concebia o juízo estético (a contemplação do belo, no fim das contas) como um âm-

7 Colocamos entre parêntesis para salvaguardar que não é como se o belo - enquanto uma qualidade qualquer etc. - fosse posto em algo que é obra. A própria obra é o belo. Cf. GADAMER, Hans-Georg. A atualidade do belo. In: Hermenêutica da obra de arte, 2010.

8 Kierkegaard talvez seja um dos intérpretes de Platão mais felizes na caracterização da ironia do personagem Sócrates. Cf. KIERKEGAARD, O conceito de ironia, p. 42 e 96.

9 GADAMER, Estética e Hermenêutica, p. 9. 
bito de conhecimento (seja teórico ou prático), além de privilegiar o belo na natureza em relação ao belo na arte. Apesar disso, gostaríamos de continuar averiguando tal hipótese traiçoeira que formulamos.

\section{JUÍzo ESTÉtICO E CONTEMPLAÇÃO: O ÂMBITO DO NÃO-CONCEITUAL}

"Delicia de las musas del cielo, ven y aplaca el caos de estos tiempos, reconcilia como antes todo lo que está en pugna y calma la furiosa discordia ] con tu celestial música de paz.

iQue sea el corazón humano un lugar de armonía!] ¿Que la primitiva naturaleza del hombre, su alma Tranquila y grande, surja de nuevo poderosa Y calme la agitación de nuestro tiempo! iViva belleza! Vuelve al miserable corazón de este pueblo,] recupera tu lugar en torno a la mesa hospitalera y en nuestros templos. [...]”

Friedrich Hölderlin. Diotima

A Crítica da Faculdade de Julgar é um desafio para quem lê na medida mesma em que deve ter sido um projeto também desafiador para Immanuel Kant. Afinal, a terceira e última crítica deveria ser a ponte entre entendimento e razão, os quais, como o próprio filósofo de Könisberg afirma, possuem âmbitos de atuação e conceitos distintos ${ }^{10}$. Kant poderia ter se contentado com tal separação abismal; todavia, se assim fizesse, a racionalidade humana restaria desarmônica e, permita-se dizer, arbitrária em seu modo de atuar no mundo. Noutro giro, ela também não seria algo uno, mas fragmentário. Isto posto, a faculdade do juízo surge como essa possibilidade de unificação da razão humana, garantindo, ao mesmo tempo e ainda assim, a autonomia das outras duas faculdades ${ }^{11}$. Nesse sentido, Kant nos diz que:

Ainda que na verdade subsista um abismo intransponível entre o domínio do conceito da natureza, enquanto sensível, e o do conceito de liberdade, com o suprassensível, de tal modo que nenhuma passagem é possível do primeiro para

10 Cf. KANT, Crítica da Faculdade do Juízo, p. 1-7. Especialmente o tópico II Do domínio da filosofia em geral. Curioso notar que o próprio Kant não submete a racionalidade prática a um paradigma semelhante ao do entendimento (a razão eminentemente teórico-científica), fato que contribui para que defendamos a própria autonomia das ciências do espírito.

11 Uma exigência semelhante pode ser encontrada, por exemplo, no Fédon de Platão e no De Anima de Aristóteles; ou seja, é uma exigência constante no pensamento filosófico. 
o segundo $[. .$.$] contudo este último deve ter uma influência sobre aquele, isto$ é, o conceito de liberdade deve tornar efetivo no mundo dos sentidos o fim colocado pelas suas leis, e a natureza em consequência tem que ser pensada de tal modo que a conformidade a leis de sua forma concorde pelo menos com a possibilidade dos fins que nela atuam segundo leis da liberdade ${ }^{12}$.

A faculdade de julgar será em seguida definida como esse médium entre ambas as faculdades superiores de conhecimento. É necessário agora compreendermos qual a “estrutura” de tal faculdade sui generis - afinal ela não possui nenhum domínio (Gebiet) próprio, ou seja, não legisla, não constitui nenhum objeto. Poder-se-ia dizer que ela fornece simplesmente regras para a reflexão, uma heurística. Isso porque o juízo referente a essa faculdade é o reflexivo, na medida em que, diferentemente do determinante, parte do particular para buscar um universal, ou seja, do fragmento de experiência para uma generalidade "legal”. É a faculdade que por excelência busca leis progressivamente universais.

Todavia, ela deve se orientar segundo algum princípio próprio. O raciocínio de Kant novamente toma o partido da necessidade de se garantir a unidade, neste caso a unidade da experiência. Afinal, o entendimento determina a natureza segundo leis universais próprias a partir de um conceito geral (allgemeinen Begriffe) de natureza, resultando daí leis empíricas particulares (besondern Empirischen Gesetze) - a constituição de objetos singulares na experiência. O trabalho da faculdade de juízo, então, será justamente o de unificar, sistematizar progressivamente tais leis empíricas particulares, de modo que nossa experiência de mundo não se perca numa fragmentariedade desnorteante para nosso entendimento. Nesse sentido, o juízo reflete sobre tal conjunto múltiplo de experiências de objetos individuais, mas não os constitui. Além disso, tal princípio não determina a unidade da natureza enquanto tal, apenas representa (vorstellen) tal unidade como necessária para nós mesmos

... como se igualmente um entendimento (ainda que não o nosso) as tivesse dada (sic) em favor da nossa faculdade de conhecimento, para tornar possível um sistema da experiência [ein System der Erfahrung] segundo leis da natureza particulares. Não como se tivéssemos que admitir efetivamente um tal entendimento (pois somente à faculdade de juízo reflexiva que esta ideia serve de

12 Cf. KANT, Crítica da Faculdade do Juízo, p. 6-7. 
princípio, mas para refletir, não para determinar); pelo contrário, desse modo, esta faculdade dá uma lei somente a si mesma e não à natureza ${ }^{13}$.

Tal princípio (ou “lei”) é o que Kant denominará de “conformidade a fins da natureza na sua multiplicidade ${ }^{14}$ [Zweckmässigkeit der Natur in ihrer Mannigfaltigkeit]". Devemos enfatizar: tal princípio é pura representação (Vorstellung) de um modo de ser da natureza, algo como uma “crença” necessária para nós, mas totalmente contingente para a natureza, dado que não é possível, para Kant, intuir-se de uma experiência particular (ou mesmo de muitas) que a natureza seja tal qual representamos. Gostaríamos de pensar tal condição humana como algo necessário para sua própria vida. O princípio de conformidade a fins dá como que segurança para nós: “o mundo não pode ser caótico!”.

Acompanhemos este gesto kantiano. É um gesto comum e fundante à/da própria história do pensamento filosófico. Não que antes da filosofia (e fora dela) exista apenas a arbitrariedade do pensamento, mas sim que é próprio da filosofia um questionamento explícito das condições e pressupostos da experiência humana no mundo. Não custa lembrarmos que versos como os de Hesíodo e Homero, se não são "filosofia" num sentido estrito, são formas muito bem acabadas de conferir ordenação à realidade. Mas não apenas isto: tais versos são fundantes da própria filosofia enquanto tal, na medida em que conferem um espaço de diálogo fecundo para o pensamento filosófico. Com isso, desejamos explicitar o fato de ser talvez próprio do ser humano a necessidade de encontrar sentido nas coisas, de forma que a vida não se mostre total e simplesmente fortuita, e que, mesmo em nossa precariedade enquanto seres finitos, possamos vislumbrar um caminho - um fim.

O princípio da conformidade a fins formal da natureza parece indicar uma resposta kantiana a tal questão. Para não nos alongarmos e nos perdermos em detalhes que não são o centro da nossa questão aqui, gostaríamos de oferecer logo uma caracterização sucinta do princípio da faculdade de juízo: ele é transcendental e simplesmente subjetivo. Transcendental porque não se funda em alguma experiência empírica, mas apenas prescreve como esta mesma pode ser objeto de nosso entendimento; subjetivo, por outro lado, pelo fato de que não prescreve nada à natureza, mas apenas a si

13 Idem, ibidem, p. 12.

14 Idem, ibidem, p. 7. 
mesma enquanto faculdade do juízo reflexivo ${ }^{15}$. Assim, “ela ${ }^{16}$ prescreve uma lei, não à natureza (como autonomia), mas sim a si própria (como heautonomia) para reflexão sobre aquela, lei a que se poderia chamar da especificação da natureza ${ }^{17 "}$. Além do mais, a realização positiva de tal princípio na atuação do juízo em uma situação qualquer concreta - “a descoberta da possibilidade de união de duas ou de várias leis da natureza empíricas, sob o princípio que integre ambas ${ }^{18 ” ~-~ n o s ~ p r o p o r c i o n a ~ u m ~ s e n t i m e n t o ~}$ de prazer (das Gefühl). E eis a chave para o problema levantado inicialmente. Para nós, isto estaria explicitado no seguinte trecho:

Na verdade nós já não pressentimos mais qualquer prazer notável ao apreendermos a natureza e a sua unidade da divisão em gêneros e espécies, mediante o que apenas são possíveis conceitos empíricos, pelos quais a conhecemos segundo as suas leis particulares. Mas certamente esse prazer já existiu noutros tempos, e somente porque a experiência mais comum não seria possível sem ele foi-se gradualmente misturado com o mero conhecimento sem se tornar mais especificamente notado. Por isso faz falta algo que, no ajuizar da natureza, torne o nosso entendimento atento à conformidade a fins desta, um estudo que conduza as leis heterogêneas da natureza, onde tal for possível, sob outras leis superiores, ainda que continuam (sic) a ser empíricas, para que sintamos prazer, por ocasião desta sua concordância em relação às nossas faculdades de conhecimento, concordância que consideramos como simplesmente contingente.

Acreditamos que Kant vislumbra nesse tocante a possibilidade concreta de que aquilo que já foi conhecido e sistematizado já não desperte prazer. Que a terra possui um formato esferoide e que gira ao redor do sol “todos” nós já sabemos; um celular já é artigo habitual de nossa vida cotidiana; o fogo simplesmente acendemos com um click do fogão se quisermos cozinhar algo - já não é um raio num dia chuvoso que pode nos oferecê-lo num arroubo de surpresa. Tais conhecimentos são relegado à evidência. Assim sendo, como evitar recair num marasmo do pensamento?

15 Cf. Idem, ibidem, p. 13-19. Aqui, Kant realizará uma “dedução transcendental” (transzendentalen Deduktion) do princípio da conformidade a fins, buscando demonstrar, por exemplo, porque não se trata de uma psicologia (entendida como ciência empírica).

16 A faculdade do juízo.

17 Idem, ibidem, p. 18.

18 Idem, ibidem, p. 20. 
O trecho acima apresenta uma saída na própria faculdade de julgar em geral enquanto móbil para sistematização da nossa experiência empírica. Todavia, é preciso que representemos uma situação tal em que a própria faculdade de julgar encontre-se, digamos, “anestesiada”. Ou seja, que ela não esteja totalmente inoperante, mas que não exerça com tamanha desenvoltura seu trabalho. Algo como uma falsa pretensão de que já se sabe tudo - um dogmatismo. Haveria um modo de a faculdade do juízo receber um impulso renovado - na realização do seu princípio - que não seja necessariamente do labor de sistematização das leis empíricas particulares ${ }^{19}$ ? Aqui diremos: é o juízo estético, a contemplação do belo que poderá ter esse papel; uma experiência de tal ordem, que "apreende" apenas a forma do objeto, quer dizer, a organização harmônica particular - sua individualidade simples e perfeitamente estruturada. O que se vê não é uma rosa, por exemplo, mas apenas algo belo.

Nesse sentido, na experiência do belo, não está em jogo o conceito de um objeto dado no entendimento. É assim que podemos compreender a advertência kantiana de que não há conhecimento aí2o ${ }^{20}$ que acontece é, arriscaremos dizer, algo superior a qualquer conhecimento objetivo de um objeto da experiência sensível. O princípio da conformidade a fins é satisfeito de um modo sui generis: dá-se com o acordo da faculdade da imaginação com o entendimento em seu livre jogo, resultando, ao fim, o prazer com a realização do princípio $^{21}$. Isto posto, o proceder metodológico das ciências da natureza parecem ficar um pouco para trás. A luz do belo é o testemunho mais imediato da harmonia do mundo; diremos: da sua verdade mais essencial. Isso escapa, realmente, a qualquer pretensão conceitual.

19 Afinal, não esqueçamos a situação formulada: é exatamente isso que está anestesiado na faculdade do juízo.

20 Cf. Idem, ibidem, p. XVII.

21 Cf. Idem, ibidem, p. 23. 


\section{REFERÊNCIAS BIBLIOGRÁFICAS:}

GADAMER, Hans-Georg. A atualidade do belo. In: Hermenêutica da obra de arte. Trad. Marco Antônio Casanova. São Paulo: WMF Martins Fontes, 2010.

A verdade nas ciências do espírito. In: Verdade e Método II: complementos e índice. $5^{\mathrm{a}}$ ed. Trad. Enio Paulo Giachini. Petrópolis: Vozes; Bragança Paulista: Editora Universitária São Francisco, 2010.

Estética e Hermenêutica. In: Hermenêutica da obra de arte. Trad. Marco Antônio Casanova. São Paulo: WMF Martins Fontes, 2010.

Verdad y Método. $4^{\mathrm{a}}$ ed. Trad. Ana Agud Aparicio e Rafael de Agapito. Salamanca: Ediciones Sígueme, 1991.

HEIDEGGER, Martin. A origem da obra de arte. Trad. Idalina Azevedo e Manuel António de Castro. São Paulo: Edições 70.

. O tempo da imagem do mundo. In: Caminhos de Floresta. $2^{\text {a }}$ ed. Trad. Alexandre Franco de Sá. Lisboa: Fundação Calouste Gulbenkian, 2012.

KANT, Immanuel. Crítica da Faculdade do Juízo. $3^{\mathrm{a}}$ ed. Trad. Valério Rohden e António Marques. Rio de Janeiro: Forense Universitária, 2012.

. Crítica da Razão prática. Trad. Artur Morão. Lisboa: Edições 70, 1994.

- Crítica da Razão pura. $8^{\mathrm{a}}$ ed. Trad. Manuela Pinto dos Santos e Alexandre Fradique Morujão. Lisboa: Fundação Calouste Gulbenkian, 2013.

KIERKEGAARD, Søren. O conceito de ironia. Trad. Álvaro Luiz Montenegro Valls. Petrópolis: Vozes, 1991, p. 42 e 96. 